\title{
First Record of the Bahamian Racer (Cubophis vudii vudii) in Joulter Cays National Park, Bahamas
}

\author{
Scott Johnson
}

Bahamas National Trust, East Bay Street, P.O. Box N-4105, Nassau, Bahamas (sjohnson@bnt.bs)

$\mathrm{O}_{\mathrm{N}}^{\mathrm{n}}$ 24 November 2015, while assisting in Piping Plover (Charadrius melodus) surveys on the northern island of Joulter Cays National Park $\left(25^{\circ} 19^{\prime} 50.34^{\prime \prime N}\right.$, $78^{\circ} 08^{\prime} 18.26^{\prime \prime W)}$, I saw a snake among some rocks and scrubby vegetation about $100 \mathrm{~m}$ from the beach. I captured and identified it as a Bahamian Racer (Cubophis vudii vudiu). About one third of its tail was missing and it had a damaged left eye. I took photographs of the snake and released it.

The Bahamian Racer is a medium sized, diurnally active snake that is endemic to and widely distributed throughout The Bahamas, although absent from San Salvador and Mayaguana (Powell 2014). This species has not been recorded from the Joulter Cays (Buckner et al. 2012), a small cluster of islands north of Andros Island. This species most likely arrived in the Joulter Cays via overwater dispersal, although whether it originated from Andros or the Berry Islands could not be determined. This record documents the first observation of a Bahamian Racer (Cubophis vudii) in Joulter Cays National Park.

\section{Literature Cited}

Buckner, S.D., R. Franz, and R.G. Reynolds. 2012. Bahama Islands and Turks \& Caicos Islands, pp. 93-110. In: R. Powell and R.W. Henderson (eds.), Island lists of West Indian amphibians and reptiles. Bulletin of the Florida Museum of Natural History 51: 85-166.

Powell, R. 2014. Cubophis vudii. Catalogue of American Amphibians and Reptiles 903: $1-15$.
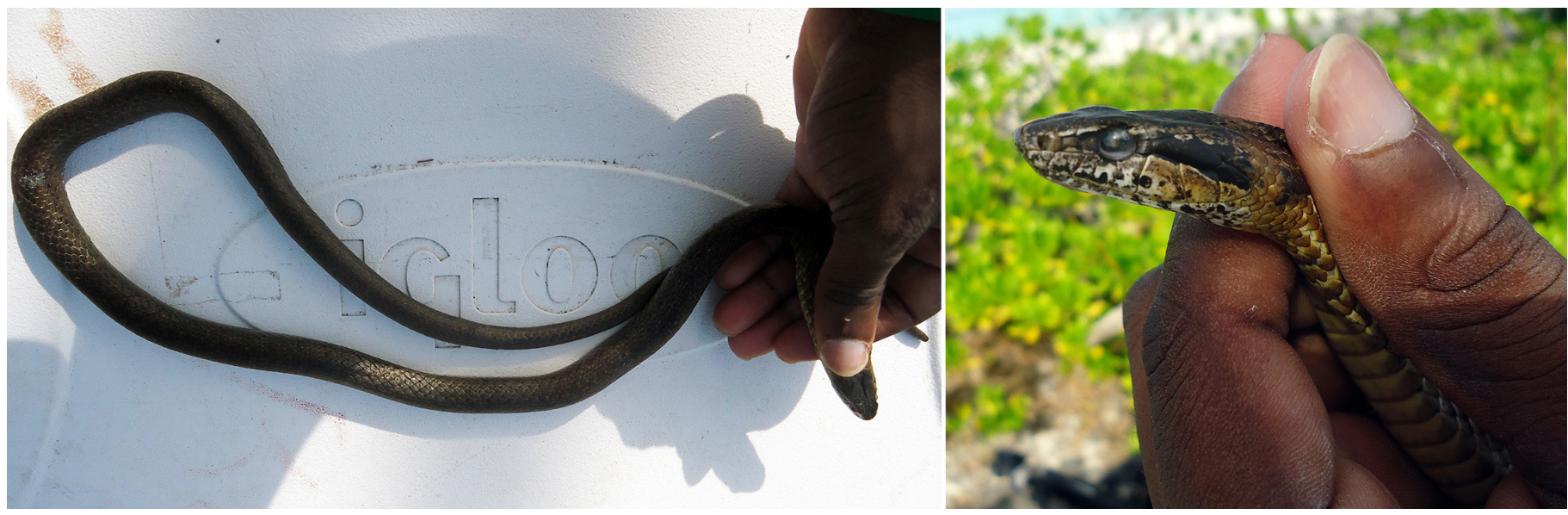

Fig. 1. A Bahamian Racer (Cubophis vudii vudii) from the northern island of Joulter Cays National Park, The Bahamas. Note the damaged left eye. Photographs by the author. 